\title{
Gestasyonel Trofoblastik Hastalıkların Kliniğimizde Retrospektif Olarak Değerlendirilmesi: Orta Dönem Sonuçlarımız
}

\author{
A Retrospective Analysis of Gestational Trophoblastic Diseases: Our Midterm Results
}

\section{Gülten ÖZGEN ${ }^{1}$, Gültekin ADANAS ${ }^{1}$}

1. Bursa Yüksek İhtisas Eğitim ve Araştırma Hastanesi Kadın Doğum ve Çocuk Hastalıkları, Bursa, Türkiye

\section{$\ddot{O Z Z E T}$}

Amaç: Bu çalışmanın amacı, gestasyonel trofoblastik hastalığı (GTH) sıklığını ve tiplerini belirlemek ve klinik parametreler ile olan ilişkisini değerlendirmektedir.

Gereçler ve Yöntem: Çalışmamıza hastanemiz kadın hastalıklar1 ve doğum kliniğine Ocak 2016 ile Haziran 2019 tarihleri arasinda yatırılarak tedavi edilen ve GTH tanısı alan 90 hasta dahil edildi.Hasta bilgileri hasta dosyaları ve bilgisayar kayıtları kullanılarak, retrospektif olarak değerlendirildi. Hastaların sosyodemografik ve klinik özellikleri, vakum küretaj öncesi ve sonrası laboratuvar test sonuçları ve patoloji sonuçları kaydedildi.

Bulgular: Çalışma süresince gerçekleşen toplam doğum sayısı 45,000 idi. Gestasyonel trofoblastik hastalık insidans $2 / 1000$ doğum olarak tespit edildi. Doksan hastanın 69'unda parsiyel $(\% 76,7)$ ve 21 'inde $(\% 23,3)$ komplet mol ve 1 hastada $(\% 1,1)$ parsiyel mol sonrası koryokarsinom gelişti.Klinik tanı hastaların \%36'sinda $(n=32)$ mol ve \%1,1'inde $(n=1)$ fetal anomali olarak değerlendirildi. Laboratuvar ve klinik bulgular açısından parsiyel ve komplet mol gebelik geçiren hastalar arasında anlamlı bir farklılık olmadığ 1 görüldü. Ancak komplet mol gebeliklerde küretaj öncesi ortalama $\beta$-hCG değeri istatistiksel olarak yüksek saptandı( $\mathrm{p}=0,088)$. Parsiyel molde en yüksek ortalama $\beta$-hCGdeğeri $46014,66 \mathrm{mIU} / \mathrm{mL}$ iken,komplet molde bu değer 76292,26 mIU/mL olarak bulundu. Hastalarda en küçük gebelik yaşı 14 yıl, en yüksek gebelik yaşı ise 47 yıl olarak saptand1.

Sonuç: Çalışma sonuçlarımıza göre, nadir olsa da,malign olma ihtimalini taşıyan GTH tanısı olan hastalar küretaj sonrasında $\beta$-hCG takiplerinin yapılması hususunda bilgilendirilmeli ve herhangi bir takip yapılmaması halinde hayati tehlike oluşturabileceği açıklanmalıdır.

Anahtar Kelimeler: gestasyonel trofoblastik hastalık, gebelik, hidatiform mol, insidans

\author{
ABSTRACT \\ Objective: In this study, we aimed to investigate the frequency \\ and type of gestational trophoblastic disease (GTD) and to eva- \\ luate clinical parameters associated with GTD. \\ Material and Methods: Between January 2016 and June 2019, \\ a total of 90 patients who were diagnosed with GTH and tre- \\ ated in the inpatient setting were included. Patient data were \\ retrospectively analyzed using medical records and database. \\ Sociodemographic and clinical characteristics of the patients, \\ laboratory test results before and after vacuum curettage, and \\ pathology results were recorded.

\section{İletişim} \\ Sorumlu Yazar: Gültekin ADANAS \\ Adres: Mimar Sinan, Bursa Yüksek İhtisas Eğitim ve Araştırma Has- \\ tanesi, 16310 Yıldırım, Bursa, Türkiye \\ Tel: +90 (224) 2955000 \\ E-Posta: gadanas@gmail.com \\ Makale Geliş: 07.12.2019 \\ Makale Kabul: 17.02.2020 \\ DOI: http://dx.doi.org/10.16948/zktipb.656568
}

Results: Throughout the study, the number of deliveries was 45,000 . The incidence of GTD was $2 / 1000$ live births. Of 90 patients, $69(76,7 \%)$ had partial, $21(23,3 \%)$ had complete, and $1(\% 1,1)$ had choriocarcinoma after partial molar pregnancy. Clinical diagnoses were molar pregnancy in $36 \%(n=32)$ and fetal anomaly in $1,1 \%(\mathrm{n}=1)$ of the patients. There was no significant difference in the laboratory and clinical characteristics between the patients with partial and complete molar pregnancy. However, the mean $\beta$-hCG level was statistically significantly higher in complete molar pregnancies before curettage $(\mathrm{p}=0,088)$. The highest mean $\beta$-hCG level was $46014,66 \mathrm{mIU} /$ $\mathrm{mL}$ in partial mole and $76292,26 \mathrm{mIU} / \mathrm{mL}$ in complete mole. The youngest maternal age was 14 years and the oldest maternal age was 47 years.

Conclusion: Our study results suggest that, although rare, patients with GTD must be informed about the $\beta$-hCG measurements on a regular basis following curettage, as the disease has the potential of malignant transformation, and be enlightened about life-threatening potential of GTD in the absence of regular follow-up.

Keywords: gestational trophoblastic disease, pregnancy, hydatidiform mole, incidence

\section{GİRIŞ}

Gestasyonel trofoblastik hastalıklar (GTH) anormal fertilizasyonun bir sonucu olarak gelișen ve trofoblastların anormal, aşırı proliferasyonu ile karakterize bir hastalık grubudur. Plasenta kaynaklı ve metastaz yapabilen bu tümör, maternal dokudan ziyade, plasenta dokusundan kaynaklanır (1). Spontan rezolüsyon ile sonuçlanabilen mol hidatiformdan yaşamı tehdit eden koryokarsinoma kadar geniş bir dağılım gösterir. Molar gebelikler karyotip, gross ve mikroskobik histopatoloji ve prognozuna göre komplet ve parsiyelmol olmak üzere iki gruba ayrilır. Gestasyonel trofoblastik neoplazi (GTN), GTH'nın invaziv veya metastatik şekli olmasına rağmen, kemoterapi ile mükemmel bir iyileşme oranına sahiptir. Molar gebeliğin vakum küretaj ile tedavisi ve ardından hastalığın seyrinin seri beta-insan koryonik gonadotropin ( $\beta$-hCG) seviyesinin takipleri ile invazivmol, koryokarsinom, plasental bölge trofoblastik tümörü ve epitelioid trofoblastik tümör içeren GTN gelişip gelişmeyeceği tayin edilir. $\mathrm{Bu}$ durum herhangi bir gebelik sonrası haftalar ve yıllar sonra ortaya çıkabilmesine rağmen, en sık görülme şekli molar gebelik sonrasıdır (2).

Erken gebelikte rutin olarak ultrasonografi (USG) kullanımı, normal gebeliğin ekarte edilmesi ve molar gebeliğin ilk trimester gibi erken dönemde tanınmasına olanak sağlamıştır. GTH'nin USG bulguları arasında, genellikle üzüm salkımı "(cluster of grapes)", ve kar firtınası "(snow storm)" görünümü 
olarak tanımlanan maternal kanla kapatılan çeşitli boyut ve şekillerde çok sayıda sonolusent kistlerle doldurulmuş bir uterin boşluk görünümü tipiktir. Manyetik rezonans görüntüleme (MRI), invaziv mol ve koryokarsinom gibi premalign ve malign olgularda invazyon derinliğini ve hastalığın yaygınlığını saptamada kullanılır (3).

Gestasyonel trofoblastik hastalık oluşumunda etkili olduğu saptanan predispozan faktörler erken menarş, parite, ilk gebelik yaşı, geçirilmiş mol gebelik öyküsü, önceki gebelikler arasındaki süre, genetik faktörler, malnütrisyon, viral enfeksiyonlar, sosyoekonomik düzey ve Asya kökenli olmaktır. Erken gebelik ve ileri anne yaşı, komplet mol hidatiforma yol açan anormal fertilizasyon ile ilişkilidir. 21 yaş altı ve 35 yaş üzeri gebeliklerde komplet mol insidans1 1.9 kat artarken, 40 yaş üzerinde 7.5 kat artış gösterir (2). 50 yaş sınırı aşıldı̆̆ında, üç gebelikten biri komplet mol ile sonuçlanır (4). Parsiyel molde ise, düzensiz menstrüel siklus, düşükler ve dört yıldan uzun süre oral kontraseptif kullanım öyküsü gözlenirken, ovülasyon indüksiyonu, beslenme ve etnik köken risk faktörü olarak rol oynamaz.

Komplet molar gebelikler diploid iken, parsiyel molar gebelikler triploid karyotipe sahiptir. Komplet mollerin \%90'1nda karyotip 46,XX iken, \%10'unda 46,XY'dir.Çekirdeksiz ovum ile iki spermin veya haploid sperm ile döllendikten sonra duplikasyonu ile oluşur ve böylece sadece paternal DNA'ya sahiptirler. Parsiyel mollerde ise karyotip triploid olup, 69,XXX veya 69,XXY'dir. Parsiyel mollerde hem paternal, hem de maternal DNA eksprese olur $(5,6)$.

$\mathrm{Bu}$ çalışmanın amacı, kliniğimizde GTH sıklığını ve tiplerini belirlemek ve klinik parametreler ile olan ilişkisini değerlendirmektedir.

\section{GEREÇ ve YÖNTEM}

Bu çalışmaya Bursa Yüksek İhtisas Eğitim ve Araştırma Hastanesi Kadın Hastalıkları ve Doğum Kliniğine Ocak 2016 ile Haziran 2019 tarihleri arasında GTH tanısı histopatolojik olarak doğrulanmış olan toplam 90 hasta alındi. Hasta bilgilerine retrospektif olarak dosya kayıtlarının incelenmesi ile ulaşıldı. Missed abortus, abortus insipiens ve inkomplet abortus ön tanıları ile yatırılıp, tedavisi yapılan ve histopatoloji sonucu mol hidatiform çıkan hastalar çalıșmaya dahil edildi. Hastaların 69'unda parsiyel mol, 21 hastada ise komplet mol gebelik tanısı mevcuttu. Mevcut kayıtlardan hastaların yaş, gravida, parite, abortus, kan grupları, $\beta$-hCG düzeyleri, vakum küretaj öncesi $\beta-h C G$ düzeyleri, serum tiroid uyarıcı hormon (TSH),tam kan sayımı sonuçları ve histopatoloji sonuçları kaydedildi.

İstatistiksel analizler SPSS versiyon 22.0 (IBM Corp., Armonk, NY, ABD) yazilım programı ile yapıld1.Elde edilen verilerin tanımlayıcı istatistik değerleri değişkenlerin dağılımlarına ve türlerine bağlı olarak ortalama, standart sapma veya medyan [IQR] ve sayı (\%)olarak hesapland1. Parsiyel ve komplet mol hastalarının klinik ve laboratuvar bulguları arasındaki farklılık, Mann-Whitney U testi ile ölçüldü. Klinik tanı ile patolojik tanı, patolojik tanı ile USG tanısı ve klinik tanı ile USG tanısı arasında- ki ilişkiler,ki-kare ile test edildi. $\mathrm{P}<0.05$,istatistiksel olarak anlamlı kabul edildi.

\section{BULGULAR}

Çalışmaya alınan 90 hastanın 69'unda parsiyel $(\% 76,7)$ ve 21 'inde $(\% 23,3)$ komplet mol patoloji sonuçları olduğu görüldü. Kan grupları incelendiğinde,hastaların \%32,4'ünde $(\mathrm{n}=22) \mathrm{ARh}(+)$ en s1k ve hastalarin $\% 1,5$ 'inde $(n=1)$ ARh (-) en az rastlanılan kan grubu olarak bulundu. Klinik tan 1 hastalarin \%36'sinda $(n=32)$ mol gebelik, \%28, 1'inde $(n=25)$ missed abortus ve $\% 1,1$ 'inde $(n=1)$ fetal anomali olarak değerlendirildi ( Tablo 1).

Tablo 1: Kategorik özelliklerin dağılımı.

\begin{tabular}{|c|c|c|c|}
\hline & & $\mathrm{n}$ & $\%$ \\
\hline \multirow{6}{*}{ Kan grubu } & $0(+)$ & 20 & 29,4 \\
\hline & $\mathrm{A}(+)$ & 22 & 32,4 \\
\hline & $\mathrm{A}(-)$ & 4 & 5,9 \\
\hline & $\mathrm{B}(+)$ & 14 & 20,6 \\
\hline & $\mathrm{AB}(+)$ & 7 & 10,3 \\
\hline & $\mathrm{AB}(-)$ & 1 & 1,5 \\
\hline \multirow{7}{*}{ Gravida } & 1 & 16 & 18,0 \\
\hline & 2 & 28 & 31,5 \\
\hline & 3 & 23 & 25,8 \\
\hline & 4 & 12 & 13,5 \\
\hline & 5 & 8 & 9,0 \\
\hline & 6 & 1 & 1,1 \\
\hline & 10 & 1 & 1,1 \\
\hline \multirow{6}{*}{ Parite } & 0 & 22 & 24,7 \\
\hline & 1 & 29 & 32,6 \\
\hline & 2 & 23 & 25,8 \\
\hline & 3 & 12 & 13,5 \\
\hline & 4 & 2 & 2,2 \\
\hline & 7 & 1 & 1,1 \\
\hline \multirow{3}{*}{ Abortus } & 0 & 61 & 69,3 \\
\hline & 1 & 26 & 29,5 \\
\hline & 2 & 1 & 1,1 \\
\hline \multirow{5}{*}{ Klinik tanı } & Anembriyonik & 11 & 12,4 \\
\hline & Fetalanomali & 1 & 1,1 \\
\hline & İnkomplet & 20 & 22,5 \\
\hline & Missed & 25 & 28,1 \\
\hline & Mol & 32 & 36,0 \\
\hline \multirow{2}{*}{ Patolojik tanı } & & 69 & 76,7 \\
\hline & Komplet & 21 & 23,3 \\
\hline
\end{tabular}

Parsiyel ve komplet mol hastalarının klinik ve laboratuvar bulguları arasındaki karşılaştırma sonuçları Tablo 2'te verildi. Tablo 2 incelendiğinde, laboratuvar ve klinik bulgular açısından parsiyel ve komplet mol gebelik hastaları arasında anlamlı bir fark olmadığı görüldü. Yalnızca komplet mol tanılı hastalarda küretaj öncesi $\beta$-hCGdüzeyi $(p=0,088)$ istatistiksel olarak anlamlı düzeyde yüksekti. Parsiyel molde tedavi öncesi $\beta$-hCGdüzeyi ortalama 46014,66mIU/mL iken, komplet molde bu $76292,26 \mathrm{mIU} / \mathrm{mL}$ ve hastalarda en küçük gebelik yaşı 14 yı1, en yüksek gebelik yaşı ise 47 yıl olarak saptand1. 
Tablo 2: Parsiyel ve kompletmol hastalarına ilişkin bulgular.

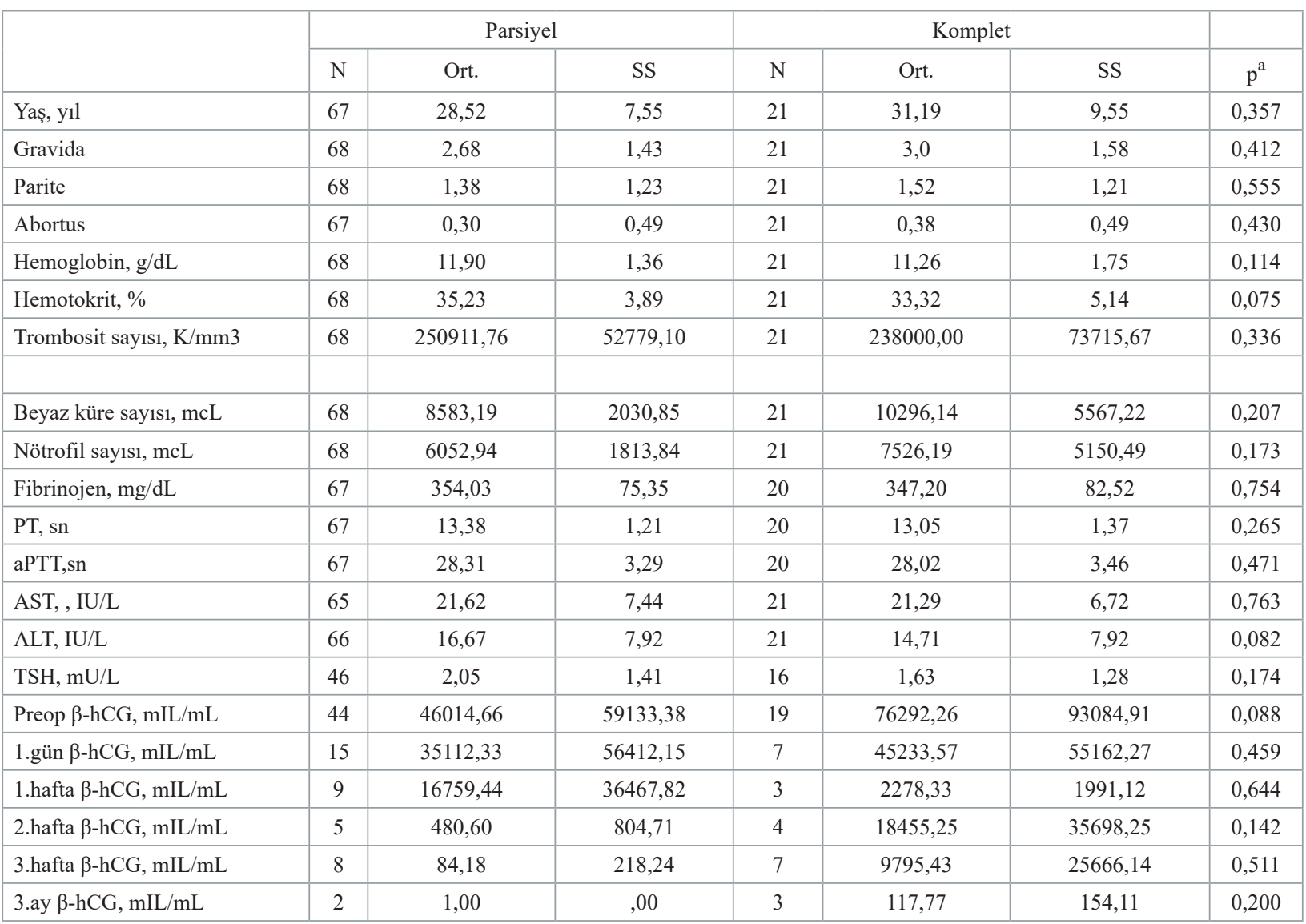

a MannWhitney U testi. PT: protrombin zamanı; aPTT: aktive parsiyel tromboplastin zamanı; AST: aspartat aminotransferaz; ALT: alanin aminotransferaz; TSH: tiroid uyarıcı hormon; $\beta$-hCG: beta-insan koryonikgonadotropin.

Patolojik tanılar ile klinik tanıların dağılımı açısından anlamlı bir fark görüldü $(\mathrm{p}=0,003)$. Sonuçlar incelendiğinde, parsiyel mol tanısında missed abortus klinik tanı sıklığının, komplet mol tanısında ise klinik mol tanı sıklığının anlamlı düzeyde daha yüksek olduğuizlendi. Buna karşın, anembriyonik, fetal anomali ve inkomplet klinik tanılarının parsiyel ve komplet mol taniları ile benzer oranda dağılım gösterdiği bulundu (Tablo 3).

Tablo 3: Klinik tanı ve patolojik tanı karşılaştırması.

\begin{tabular}{|c|c|c|c|c|c|c|}
\hline & \multicolumn{2}{|c|}{ Parsiyel } & \multicolumn{2}{|c|}{ Komplet } & \multirow[b]{2}{*}{$\mathrm{p}^{\mathrm{a}}$} \\
\hline & & $\mathrm{N}$ & $\%$ & $\mathrm{n}$ & $\%$ & \\
\hline \multirow{5}{*}{ Klinik tanı } & Anembriyonik & 10 & 14,7 & 1 & 4,8 & \multirow{5}{*}{0.003} \\
\hline & Fetalanomali & 1 & 1,5 & 0 & 0,0 & \\
\hline & İnkomplet & 17 & 25,0 & 3 & 14,3 & \\
\hline & Missed & 23 & 33,8 & 2 & 9,5 & \\
\hline & Mol & 17 & 25,0 & 15 & 71,4 & \\
\hline \multicolumn{2}{|l|}{ Total } & 68 & & 21 & & \\
\hline
\end{tabular}

a Fisher-Freeman-Halton testi.

\section{TARTIŞMA}

Mol hidatiform insidansı, literatür taramalarında farklılıklar göstermektedir. Genetik ve etnik faktörler ile bölgesel beslenme alışkanlıkları ve sigara kullanımı açısından görülen farklılıklar nedeniyle, istatistiksel verilerde de değişkenlik meydana gelmektedir. Mol gebelik insidansı Kuzey Amerika ve Avrupa'da 100,000 gebelikte 60 ila 120 arasında değișmekle birlikte, Güneydoğu Asya ve Japonya'da bu oran 1000 gebelikte 2'dir (7). Mol gebelik insidans siklığını ke- sin olarak arttırdığ 1 bilinen risk faktörlerinden olan ileri anne yaşı ile prevelans 5 ila 10 kat artar. Önceki gebeliklerde spontan düşüklerin olması, A vitaminden fakir beslenme ve hayvansal yağlar içeren beslenme ve sigara kullanımı mol gebelik sıklığını arttırır (8). Komplet mol hidatiformun bilinen etiyolojik risk faktörleri ise ileri anne yaşı ( $>40$ yaş) ve daha önce molar gebelik öyküsünün olmasıdır. Komplet mol öyküsünün olmas1 19q.1 kromozomundaki NLRP7 geni ile ilişkili bulunmuştur (9).

Tersiyer bir merkez olan kliniğimizde 42 aylik dönemde gerçekleşen toplam 45,000 doğumun 90 'inda mol hidatifom tanisi kondu. $\mathrm{Bu}$ oran $\% 0.2$ olarak hesaplandı. Budak ve ark. (10) tarafindan Ocak 2012 ile Ocak 2014 tarihleri arasında Diyarbakır Kadın Doğum ve Çocuk Hastalıkları Hastanesi'nde yapılan çalışmada, histopatolojik inceleme sonucu tanı konulan 87 mol hidatiform olgusu-retrospektif olarak tarand1 ve bu oran iki y1llık dönemde 1000 doğumda 2.2 olarak saptandı. Bu sonuç, bizim çalışma sonuçlarımız ile benzerlik göstermektedir. Barut ve ark. (11) tarafindan Harran Üniversitesi Tip Fakültesi Kadın Hastalıkları ve Doğum Kliniğinde Ocak 2015 ile Ocak 2018 tarihleri arasında yapılan bir başka çalışmada, GTH tanısı patoloji sonucu ile doğrulanmış alan 89 hastada GTH insidans1 22,6/1000 doğum olarak oldukça yüksek düzeyde saptandı. Gezginç ve ark. (12) tarafindan 2005 yılında Konya ilinde yapılanbir çalışmada da, GTH 1000 doğum için 3.35 olarak bulundu. Lurain ve ark. (13) tarafindan yapılan bir çalışmada, GTH'nin 20 yaş altında görülme riskinin 1.5 kat, 40 yaş üstünde görülme riskinin ise 5.2 kat arttı̆ğ bildirildi. Çalışmamızdaki hastaların ortalama yaş aralığ 
celendiğinde, parsiyel mol tanısı konulan olguların yaş ortalamas1 28,52 $\pm 7,55$ y1l, komplet mol tanis1 konulan olguların ise $31,19 \pm 9,55$ olduğu belirlendi $(p=0,357)$. Maternal yaş için en küçük yaşın 14, en büyük yaşın ise 47olduğu tespit edildi. Diğer yaş grupları ile karşılaştırıldığında, üreme çağındaki yaş grubunda GTH daha s1k görüldü. Budak ve ark. (10) tarafindan yap1lan çalışmada, ortalama mol gebelik yaşının 28 olduğu belirlendi.

Serum $\beta$-hCG düzeyleri, GTH tanısında ve tedavisinde önemli bir rolü olan, trofoblastların etkinliğini gösteren bir belirteçtir. Mol gebeliklerde tipik olarak, aynı gestasyon zamanındaki normal ve ektopik gebeliklere kıyasla, $\beta$-hCG düzeyi oldukça yükssektir. Komplet molde $\beta$-hCG düzeyleri $100,000 \mathrm{mIU} / \mathrm{mL}$ üzerinde olup, parsiyel mole oranla oldukça yüksektir. Çalışmamızda ameliyat öncesi maksimum $\beta$-hCG düzeyi $345,836 \mathrm{mIU} / \mathrm{mL}$ ile komplet molde saptanırken, parsiyel molde en yüksek $\beta$-hCG düzeyi 46,014mIU/ $\mathrm{mL}$ ve komplet molde $76,292 \mathrm{mIU} / \mathrm{mL}$ olarak bulundu.

Kan gruplarının belirlenmesi, komplet veya parsiyel mol nedeniyle başvuran hastalarda yapılacak olan vakum küretaj işlemi sırasında oluşabilecek kan kaybını telafi etmek ve Rh (D) negatif hastalara uygulanacak anti-D immünglobülin ihtiyacı için önemlidir. Bagshwe ve ark. (14) tarafindan yapılan bir çalışmada, molar gebeliklerde maternal A kan grubuna daha sık rastlandığı bildirildi. Bizim çalışmamızda ise, maternal kan grupları incelendiğinde, en sık ARh (+) $(\% 32,4)$ ve en az olarak da $(\% 1,5)$ ARh (-) kan grubu bulundu. Barut ve ark. (11) tarafindan yapılan çalışmada, 36 hastanın $(\% 40,5) 0$ grubuna, 35 hastanın ise $(\% 39,3)$ A grubuna sahip oldukları belirlendi. Budak ve ark. (10) da hastaların 32'sinde (\%36,.8) $0 \mathrm{Rh}(+)$, 24 'ünde $(\% 27, .6) \mathrm{ARh}(+)$ kan grubu tespit etti.

Braga ve ark. (15) tarafindan yapılan bir çalışmada, GTH ile ilişkili komplikasyonların başında vaginal kanama, preeklampsi ve hipertiroidinin geldiği bildirildi. Çalışmamızda hastalar arasında tiroid fonksiyon testleri açısından istatiksel olarak anlamlı bir fark saptanmadi. Parsiyel molde ortalama TSH düzeyi 2,05+1,41 mU/L iken, komplet molde 1,63+-1,28 mU/L idi $(\mathrm{p}=0,174)$.

Gestasyonel koryokarsinom sitotrofoblast ve sinsityotrofoblastların malign formudur ve kompletmol, term gebelik, abortuslar ve ektopik gebelik sonrasi gelişebilir (16). Gestasyonel koryokarsinom hızlı seyirli olup, metastatik hastalıkta erken tedavi edilmezse öldürücü olabilir. Koryokarsinomda venöz metastazlar yoluyla alt genital sisteme ve akciğerlere metastaza s1k rastlanır (17). Bizim çalışmamızda parsiyel mol sonras1 koryokarsinom gelişen 32 yaşındaki bir olgumuza histerektomi uyguland. Ancak takiplerinde vajen ve akciğer metastazı gelişen hastamıza EMA-CO protokolü (etoposid, metotreksat, aktinomisin D, siklofosfamit, vinkristin) uyguland ve tıbbi onkoloji tarafindan tedavisi düzenlenerek, takipleri yapıldı.

\section{SONUC}

Sonuç olarak, etiyolojisi tam olarak bilinmeyen, ancak maligniteye dönüşme olasıllğı olan bu hastalıkları önlemek amaciyla etkin kontrasepsiyon yöntemlerinin kullanımı ve toplumun tüm kesimlerine ulaşabilen antenatal takip ve izlem programları yaygınlaştırılmalıdır. $\mathrm{Bu}$ hastalar, $\beta \mathrm{hCG}$ düzeyleri tamamen sifirlanana kadar mutlaka monitörize edilerek izlenmelidir. Özellikle insidansın yüksek olarak izlendiği bölgelerde erken ve geç gebelik yaşı, tekrarlayan spontan düşükler, beslenme alışkanlıkları, sigara kullanımı, hayvansal gidalarla ağırlıklı beslenme gibi faktörler göz önünde bulundurularak, takip ve tedavi planlanmalıdır

\section{KAYNAKLAR}

1. Comparison between vacuum aspiration and forceps plus blunt. Asuka Sato,Hirokazu Usui ,MakioShozu. Taiwanese Journal of Obstetrics\&Gynecology 58 (2019) 650-655.

2. Khorn E.Practice bulletin No.53-Diagnosis and treatment of gestational trophoblastic disease. Obstet Gynecol.2004 Dec;104 (6)14223 .

3. Alampady K.P. Shanbhogue,,NeerajLalwani,, Christine O. Menias. Gestational Trophoblastic Disease. RadiolClin N Am 51 (2013) 1023-1034.

4. Seckl MJ, Sebire NJ, BerkowitzRS. Gestational trophlastic disease. Curr Obstet Gynecol. Rep 2014;3 40-43.

5. Braga A, Mora P, de Melo AC, Nogueira-Rodrigues A, Amim-Junior J, Rezende-Filho J, Seckl MJ. Challenges in the diagnosis and treatment of gestational trophoblastic neoplasia worldwide. World J . 2019 Feb 24;10 (2):28-37.

6. Yuk JS, Baek JC, Park JE, Jo HC, Park JK, Cho IA. Incidence of gestational trophoblastic disease in South Korea: a longitudinal, population-based study. PeerJ. 2019;7:e6490.019 Feb 24;10 (2):28-37.

7. Lurain JR. Gestational Trophlastic disease I:epidemiology, pathology, clinical presentation and diagnosis of gestational trophlastic disease, and management of hydatiform mole.Am J Obstet Gynecol.2010;203:531-539.

8. Sassan Ghassemzadeh, Michael Kang. HydatidiformMole. NCBI Bookshelf. A service of theNational Library of Medicine, NationalInstitutes of Health. StatPearls. Treasure Island (FL): Stat Pearls Publishing; 2019Jan

9. Goldstein DP,.Berkowitz RS. Current Management of Gestational Trophoblastic Neoplasia. Hematol Oncol Clin N Am 26 (2012) 111-131)

10. Budak MŞ., Kaya C., Şentürk MB , Akgol S , Pektaş MK, Tunç SY. , Göklü MR.Kliniğimizde tanı alan parsiyel ve komplet mol hidatiform olgularının retrospektif analizi. Haydarpaşa Numune Eğitim ve Araştırma Hastanesi Tıp Dergisi 2016; 56 (2)

11. Barut M.U., Sak S., Sak M.E. Retrospective Assessment of Molar Pregnancy Cases Admitted to Our Clinic Dicle Tip Dergisi / Dicle Med J (2018) 45 (4) : 431-437

12. Gezginç K, Görkemli H., Celik C. Acar A., Colakoğlu MC. Kliniğimizdeki Gestasyonel Trofoblastik Hastalıklı Vakaların Analizi. Türk Jinekolojik Onkoloji Dergisi Haziran 2004, Cilt 7, Sayı 2, Sayfa 70-74

13. Lurain JR. Pharmacotherapy of gestational trophoblastic disease. Expert Opin Pharmacother. 2003; 4: 2005- 17.

14. Bagshwe KD, Dent J, Webb J: Hydatiform mole in United Kingdom 1973-1983. Lancet. 1986; 2: 673- 7.

15. Braga A, Moraes V, Maestá I, Amim Júnior J, Rezende-Filho Jd, Elias $\mathrm{K}$, et al.: Changing trends in the clinical presentation and management of complete hydatidiform mole among Brazilian women. Int J Gynecol Cancer. 2016; 26: 984-90)

16. Mangla, M.; Singla, D.; Kaur, H.; Sharma, S. Unusual clinical presentations of choriocarcinoma: A systematic review of case reports. Taiwan. J. Obstet. Gynecol. 2017, 56, 1-8.

17. Rao, A.L.; Devi, R.S. An unusual presentation of choriocarcinoma. Int. J. Reprod. Contracept. Obstet. Gynecol. 2017, 6, 1668. Seidler, D.; Franklin, M. Metastatic Choriocarcinoma to the Lung: Changing Dogma. Chest 2016, 150, 765A 